\title{
Five Very Fast Ways to Better Understand a New Product or Market
}

\author{
Ethan Mollick (University of Pennsylvania)
}

KEYWORDS: Entrepreneurship, Innovation, Teaching Methods.

Many entrepreneurship classes focus on student business ideas. The goal of this exercise is to expose students to a variety of tests to validate a business idea quickly: setting up the tests in one class session so that they have initial feedback by the next time the class meets (within 24 hours). This allows students to quickly get their feet wet as they begin the journey of developing their business ideas.

\section{Learning Objectives:}

- Students will be able to apply methods of getting rapid feedback on ideas, including: surveys, interviews and $A / B$ testing

- Students will understand why it is important to get outside validation their ideas

- Students will be able to refine business ideas

The material can also be used as a supplement to classes that focus on ideation (such as product design classes) or those that focus on Lean Startup techniques.

\section{Running the Exercise:}

Distribute the attached document Five Very Fast Ways to Better Understand a New Product or Market to your students.

This exercise is typically done after students have generated business ideas, and ideally when students are divided into teams around particular ideas. It can be used in conjunction with lessons on business planning for startups to help students focus on what aspects of their ideas they need to test. It can also be used to help test hypotheses (in the Learn Startup Method) or assumptions (in Discovery Driven Planning).

A more advanced version of this exercise would be to use it as part of a formal Customer Discovery process in a class using this technique. If you are using the exercise in this way, then students should have already examined their assumptions and learned the basics of hypothesis generation. You would then give them the assignment of generating a testable hypothesis that they could examine using one of these methods, and ask them to produce a paper that would examine both the hypothesis (for example, whether it was testable, falsifiable, and parsimonious) and whether their test validated or invalidated by the results of their test.

I would typically devote 30 minutes of a 90 -minute class to introducing these methods, and the remainder of the time to allowing group work around one of these methods (while providing feedback and guidance). Students should select the method that works best for the major issues they have with the idea.

Debriefs occur in the second class period.

\section{Discussion:}

Teams should each present the outcomes of their test, focusing on four points:

1. What questions or assumptions they were testing with their approach

2. How they went about their test

3. What they learned from the test

4. How what they learned impacts their idea: Did it validate the idea? Suggest a pivot? Convince them to abandon the idea?

Generally, the instructor need only act as a facilitator, helping the students get through these questions.

Alternate Use: You can simply distribute the handout as a tool for students exploring business ideas as well, without the exercise.

\section{More ideas:}

Business and entrepreneurship professors can find more ideas for enriching the classroom experience here 
(https://eiexchange.com/eix-in-class) .

Additional Search Terms: entrepreneurship courses, teaching ideas, teaching resources, classroom ideas, entrepreneurship classes, business schools, business school classes, entrepreneurship students, professors 